\title{
ANTIBIOTIC RESISTANCE PATTERN OF GROUP-A BETA-HEMOLYTIC STREPTOCOCCI ISOLATED FROM NORTH INDIAN CHILDREN
}

\author{
AMITA JAIN, VIVEK KUMAR SHUKLA, VANDANA TIWARI, RASHMI KUMAR ${ }^{1}$
}

\section{ABSTRACT}

BACKGROUND: The current resistance pattern of GABHS (group-A beta-hemolytic streptococci) in India has not been discussed. AIM: To fill the above-mentioned void, we planned this study to determine the prevalence and degree of antibacterial resistance in GABHS isolates. SETIINGS AND DESIGN: Children with acute pharyngo-tonsillitis who had not received antibiotic in the preceding week, attending the pediatric OPD, were prospectively enrolled over a period of 1 year. Throat swabs were collected from each child and transported to microbiology laboratory, as early as possible. MATERIALS AND METHODS: A throat swab culture for GABHS was done. All GABHS were subjected to antibiotic susceptibility and minimum inhibitory concentration (MIC) test according to Clinical Laboratory Standard Institute (CLSI) guidelines. RESULTS: In the present study, $12.6 \%$ (55/435) of the children with acute pharyngo-tonsillitis had throat swab culture positive for GABHS. The prevalence of macrolide resistance was $10.2 \%$. The MIC50 for macrolide-resistant strain was $0.5 \mu \mathrm{g} / \mathrm{mL}$ (range, $0.125-8 \mu \mathrm{g} / \mathrm{mL}$ ), and MIC90 was $8 \mu \mathrm{g}$ / $\mathrm{mL}$ (range, $0.125-8 \mu \mathrm{g} / \mathrm{mL}$ ). Tetracycline and co-trimoxazole resistances were $24.5 \%$ and 12.2\% respectively. The values of MIC50 for tetracycline- and co-trimoxazole-resistant strains were $4 \mu \mathrm{g} / \mathrm{mL}$ (range, $0.125-32 \mu \mathrm{g} / \mathrm{mL}$ ) and $2 \mu \mathrm{g} / \mathrm{mL}$ (range, $0.25-8 \mu \mathrm{g} / \mathrm{mL}$ ) respectively. All isolates were sensitive to penicillin $G$ and chloramphenicol on disc diffusion test. However, their MIC50 was $0.032 \mu \mathrm{g} / \mathrm{mL}$ (range, 0.012-0.125 $\mu \mathrm{g} / \mathrm{mL}$ ) and $2 \mu \mathrm{g} / \mathrm{mL}$ (range, $0.25-4 \mu \mathrm{g} / \mathrm{mL}$ ) respectively. CONCLUSION: High prevalence of antimicrobial resistance found among GABHS needs a longitudinal surveillance of isolates from different centers in India.

Key words: Group-A beta-hemolytic streptococci, pharyngo-tonsillitis, streptococcus hemolyticus

\section{INTRODUCTION}

Acute respiratory infections are still a major health problem in most developing countries. Group-A streptococci are the leading cause

Departments of Microbiology and ${ }^{1}$ Pediatrics, CSM Medical University, Lucknow, UP, India.

\section{Correspondence:}

Dr. Amita Jain, Department of Microbiology,

CSM Medical University, Lucknow - 226 003, India.

E-mail: amita602002@yahoo.com of acute bacterial pharyngitis ${ }^{[2]}$ and primary skin infections. Impetigo is the most frequently occurring disease, especially in tropical climates. Inappropriate antibiotic treatment for pharyngitis is becoming a major issue; hence only true group-A beta-hemolytic streptococcal infections proven by rapid antigen test or culture should be treated with antibiotics.

Penicillin remains the treatment of choice for group-A beta-hemolytic streptococci 
(GABHS) pharyngitis, ${ }^{[1,2,5]}$ and macrolide are recommended only for patients who are allergic to penicillin. Erythromycin resistance in GABHS ranges from as low as $1.3 \%-5 \%$ to as high as $>45 \%$ as reported from outbreaks in Finland, ${ }^{[9]}$ Sweden, ${ }^{[6]}$ and Japan. ${ }^{[12]}$ High rates of resistance have also been reported sporadically from Australia (17\%), ${ }^{[15]}$ United Kingdom $(22.8 \%),{ }^{[19]}$ Taiwan (rate not specified), and Italy (40\%). ${ }^{[9]}$ Resistance to tetracycline and co-trimoxazol has been reported to be high, making them virtually unusable as an alternative for the treatment of GABHS infection. ${ }^{[9]}$

Antimicrobial drugs for GABHS are used to avoid suppurative complication, prevent rheumatic fever, abort person-to-person transmission, and diminish the signs and symptoms associated with these infections. The current resistance pattern of GABHS in India has never been evaluated. Hence we planned this study to determine the prevalence and degree of antibacterial resistance in GABHS isolates.

\section{MATERIALS AND METHODS}

\section{Study population}

Children with acute pharyngo-tonsillitis attending the pediatric OPD who had not received antibiotic in the preceding 1 week and who consented to participate were prospectively enrolled over a period of 1 year (July 2005 to June 2006). An institutional ethical clearance was obtained.

\section{Sample collection and transport}

Throat swabs were collected. Each swab was transported to microbiology laboratory in screwcapped test tube with Stuart's transport medium within half an hour.

Culture, identification, and antibiotic susceptibility testing

Throat swab from each patient was plated on trypticase soy blood agar with $5 \%$ sheep blood. Inoculated plates were incubated overnight at $37^{\circ} \mathrm{C}$ under $5 \% \mathrm{CO}_{2}$ effect and examined for the presence of GABHS by the formation of distinct zones of beta-hemolysis around colonies. ${ }^{[7]}$ GABHS strains were identified on the basis of zone diameter around bacitracin disk (10 $\mu \mathrm{g} /$ disk) on susceptibility testing as recommended by $\mathrm{CLSI} .{ }^{[4]}$ In this study, we defined GABHS strains only using the bacitracin test, since serotyping is not available in our routine practice. Bacterial colonies producing no hemolysis were considered as bacitracin resistant.

Disks susceptibility testing was performed according to the guideline of CLSI. ${ }^{[4]}$ MuellerHinton sheep blood agar was inoculated with a suspension of organism. Disks with $15 \mu \mathrm{g} / \mathrm{disk}$ of erythromycin, $30 \mu \mathrm{g} /$ disk of tetracycline, 50 $\mu \mathrm{g} /$ disk of chloramphenicol, $25 \mu \mathrm{g} /$ disk of cotrimoxazol, and 10 units/disk of penicillin $\mathrm{G}$ were dispensed on the Muller Hinton Agar (MHA) with $5 \%$ sheep blood, and zone diameters were determined according to CLSI standard.

\section{Minimum inhibitory concentration}

Susceptibility of the strain to erythromycin, chloramphenicol, tetracycline, co-trimoxazol, and penicillin $\mathrm{G}$ was tested by broth dilution method. All the antibiotics were procured from Himedia (Mumbai, India). The antibiotics were tested at concentrations ranging from 0.012 to $0.125 \mu \mathrm{g}$ of penicillin $/ \mathrm{mL}, 0.125$ to $4 \mu \mathrm{g}$ of erythromycin/ $\mathrm{mL}, 0.125$ to $16 \mu \mathrm{g}$ of tetracycline $/ \mathrm{mL}, 0.25$ to 
$2 \mu \mathrm{g}$ of chloramphenicol $/ \mathrm{mL}$, and 0.25 to $4 \mu \mathrm{g}$ of co-trimoxazol $/ \mathrm{mL}$. The following Minimum inhibitory concentration (MIC) breakpoints were adopted according to CLSI guidelines ${ }^{[4]}$ : penicillinsusceptible, $\leq 0.125 \mu \mathrm{g} / \mathrm{mL}$; and resistant, $\geq 0.25 \mu \mathrm{g} / \mathrm{mL}$; erythromycin-susceptible, $\leq 0.25$ $\mu \mathrm{g} / \mathrm{mL}$; and resistant, $\geq 1 \mu \mathrm{g} / \mathrm{mL}$; tetracyclinesusceptible, $\leq 2 \mu \mathrm{g} / \mathrm{mL}$; and resistant, $\geq 8 \mu \mathrm{g} /$ $\mathrm{mL}$; chloramphenicol-susceptible, $\leq 4 \mu \mathrm{g} / \mathrm{mL}$; and resistant, $\geq 16 \mu \mathrm{g} / \mathrm{mL}$; and co-trimoxazolsusceptible, $\leq 1 \mu \mathrm{g} / \mathrm{mL}$; and resistant, $\geq 2 \mu \mathrm{g} /$ $\mathrm{mL}$.

A control plate was inoculated for each isolate to confirm the purity of the culture and the initial inoculum density. MICs were interpreted by using the CLSI breakpoints for streptococci.

\section{Data analysis}

Data was analyzed on WHO net microbiology laboratory database software (version 5.1).

\section{RESULTS AND DISCUSSION}

Of the 435 children (age, 2-12 years)

Table 1: Prevalence of streptococcal sore throat according to age $(\mathbf{n}=\mathbf{4 3 5})$

\begin{tabular}{lcc}
\hline Age group (in year) & Positive for GABHS & Cases enrolled \\
\hline$>2-4$ & $19(11.9)$ & 159 \\
$>4-6$ & $11(14.1)$ & 78 \\
$>6-8$ & $11(13.7)$ & 80 \\
$>8-10$ & $6(8.7)$ & 69 \\
$>10-12$ & $8(16.3)$ & 49 \\
Total & $55(12.6)$ & 435 \\
\hline
\end{tabular}

enrolled in the study, 55 (12.6\%) were culture positive for GABHS [Table 1]. Of these 55, 6 isolates lost their viability during storage and subculturing. Resistance pattern of remaining 49 isolates was tested against penicillin G, erythromycin, chloramphenicol, tetracycline, and co-trimoxazole. The overall rate of macrolide resistance was $10.2 \%$. Of these 49 GABHS isolates, 12 (24.4\%) were resistant to tetracycline, followed by co-trimoxazole $(6$, $12.2 \%)$ and erythromycin $(5,10.2 \%)$ [Table 2]. All the isolates were sensitive to penicillin $\mathrm{G}$ and chloramphenicol. Tetracycline and cotrimoxazol resistances were $24.5 \%$ and $12.2 \%$ respectively [Table 2].

The $\mathrm{MIC}_{50}$ for erythromycin-resistant strains was $0.5 \mu \mathrm{g} / \mathrm{mL}$ (range, $0.125-8 \mu \mathrm{g} / \mathrm{mL}$ ), and $\mathrm{MIC}_{90}$ was $8 \mu \mathrm{g} / \mathrm{mL}$ (range, $0.125-8 \mu \mathrm{g} / \mathrm{mL}$ ). The values of $\mathrm{MIC}_{50}$ for tetracycline- and cotrimoxazole-resistant strains were $4 \mu \mathrm{g} / \mathrm{mL}$ (range, $0.125-32 \mu \mathrm{g} / \mathrm{mL}$ ) and $2 \mu \mathrm{g} / \mathrm{mL}$ (range, 0.25-8 $\mu \mathrm{g} / \mathrm{mL}$ ) respectively, while values of $\mathrm{MIC}_{90}$ for these antibiotics were $16 \mu \mathrm{g} / \mathrm{mL}$ (range, $0.125-32 \mu \mathrm{g} / \mathrm{mL}$ ) and $4 \mu \mathrm{g} / \mathrm{mL}$ (range, $0.25-8 \mu \mathrm{g} / \mathrm{mL}$ ) respectively. MIC values for antimicrobials are given in Table 2.

Our study shows that prevalence of antibioticresistant group-A streptococci has emerged rapidly in northern India. ${ }^{[13]}$ Several reports of erythromycin resistance ranging from $1 \%$ to

Table 2: Antimicrobial resistance pattern for GABHS by disk diffusion and broth dilution method $(n=49)$

\begin{tabular}{lccccccc}
\hline Drugs & \multicolumn{3}{c}{ Disk diffusion } & & \multicolumn{3}{c}{ Broth dilution $(\mu \mathrm{g} / \mathrm{ml})$} \\
\cline { 2 - 4 } \cline { 6 - 8 } & $R$ & $I$ & $S$ & & MIC50 & MIC90 & Range \\
\hline Erythromycin & $5(10.2)$ & $4(8.2)$ & $40(81.6)$ & & 0.5 & 8 & $0.125-4$ \\
Tetracycline & $12(24.4)$ & $7(14.3)$ & $30(61.4)$ & & 4 & 16 & $0.125-16$ \\
Co-Trimoxazole & $6(12.4)$ & 0 & $43(87.7)$ & & 2 & 4 & $0.25-4$ \\
Chloramphenicol & 0 & 0 & $49(100)$ & & 2 & 4 & $0.25-2$ \\
Penicillin-G & 0 & 0 & $49(100)$ & & 0.032 & 0.064 & $0.012-0.125$ \\
\hline
\end{tabular}

$\mathrm{R}=$ resistant, l=intermediate, $\mathrm{S}=$ susceptible, Figures in parentheses are in percentage 
$18 \%$ among group-A streptococci have been published. ${ }^{[6,12-17]}$ An increasing trend toward erythromycin resistance was reported from Japan, ${ }^{[6]}$ where the frequency of erythromycinresistant group-A streptococci first increased from $70 \%$ to $80 \%$ and then decreased once the use of erythromycin was reduced. Erythromycin resistance ranges from as low as $1.3 \%-5 \%$ to as high as $>45 \%$ during outbreaks in Finland, ${ }^{[14]}$ Sweden, ${ }^{[6]}$ and Japan. ${ }^{[12]}$ High rates of resistance have also been reported sporadically in Australia (17\%) ${ }^{[15]}$ and United Kingdom (22.8\%). ${ }^{[9]}$ Prevalence of macrolide resistance was $10.2 \%$ in our study. The importance of identifying macrolide resistance in GABHS is dependent upon whether these antibiotics are used for treatment and if in vitro resistance results in clinical failure. At present, erythromycin is recommended as alternative treatment for patients with GABHS pharyngitis who are allergic to penicillin. ${ }^{[1,5]} A$ continuous surveillance will be helpful in management of such cases.

The present study reports $24.5 \%$ tetracycline resistance in GABHS. In 1954, Lowbury and Cason $^{[17]}$ reported the first isolate of GABHS from a unit in Birmingham, England, that was resistant to tetracycline. Subsequent reports showed that $5 \%$ to $25 \%$ of the GABHS isolated from US ${ }^{[4-15]}$ and $17 \%$ of the GABHS isolated from Spain were resistant to tetracycline. The prevalence of co-trimoxazol resistance found in our study was $12.2 \%$. Though resistance to this drug is low, it cannot be used because of the intrinsic resistance ${ }^{[17]}$ of group- $A$ streptococci. All isolates were susceptible to chloramphenicol. No GABHS were found to be penicillin resistant in our study, reinforcing the fact that the penicillin resistance has not developed in this organism in northern India, in spite of frequent penicillin use.

\section{REFERENCES}

1. American Academy of Pediatrics. Group-A streptococcal infection. In Redbook: Report of the committee on Infectious Diseases. vol. 3. Elk Grove Village: American Academy of Pediatrics; 2003. p. 526-36.

2. Bruton S, Pichichero. Consideration in the use of antibiotics for streptococcal pharyngitis. J Fam Pract 2006;supply:S9-16.

3. Clinical laboratory standard institute. Performance standards for antimicrobial disk susceptibility tests: Approved standard M17-A20. Wayne, PA. USA: Committee for clinical Laboratory Standards; 2005.

4. Cornaglia G, Ligozzi M, Mazzariol A, Valentini M, Orefici G, Fontana R, et al. Rapid increase of resistance to erythromycin and clindamycin in Streptococcus pyogenes in Italy 1993-1995. Emerg Infect Dis 1996;2:339-42.

5. Dohar JE. Management of group A beta-hemolytic streptococcal pharyngotonsillitis in children. $J$ Fam Pract Book I 2006;55:S1-11.

6. Gerber MA. Antibiotic resistance: Relationships to persistence of group A streptococci in the upper respiratory tract. Pediatrics 1996;97:971-5.

7. Johnson DR, Kaplan EL. Laboratory diagnosis of group A Streptococcal infections. Geneva: WHO; 1996.

8. Kaya EG, Yucel M, Karakoc AE. Investigation of erythromycin resistance and resistance phenotypes in group A beta hemolytic streptococci. Mikrobiyol Bul 2006;40:161-8.

9. Lloyd CA, Jacob SE, Menon T. Antibiotic resistant beta-hemolytic streptococci. Indian J Pediatr 2007;74:1077-88.

10. Lowbury EJ, Cason JS. Aureomycin and erythromycin therapy for Streptococcus pyogenes in burns. Br Med J 1954;2:914-5.

11. Linder JA, Bates DW, Lee GM. Antibiotic 
treatment of children with sore throat. JAMA 2005;294:2354-6.

12. Mariani-Kurkdjian $P$, Doit $C$, Deforche $D$, Brahimi $\mathrm{N}$, Francois $\mathrm{M}$, Francois $\mathrm{M}$, et al. Current Streptococcus pyogenes sensitivity responsible for acute tonsillopharyngitis in France. Press Med 2004;33:703-6.

13. Rajesh KR, Gordon RC. Streptococcal pharyngitis: Is penicillin still the drug of choice? Indian J Pediatr 1996;63:437-40.

14. Senses Z, Baysallar M, Gur D, Doganci L. Macrolide antibiotic resistance rates and phenotypes of group A beta hemolytic streptococci isolated between the years 1999-2000 and 2001-2002.
Mikrobiyol Bul 2003;37:225-34.

15. Seppala $H$, Nissinen A, Jarvinen $H$, Huovinen $\mathrm{S}$, Henriksson $\mathrm{T}$, Herva $\mathrm{E}$, et al. Resistance to erythromycin in group-A streptococci. N Engl J Med 1992;326:292-7.

16. Vollater MM, Soriano NJ, Salvert LM. Group A streptococcal bacteremia outcome and prognostic factors. Rev Esp Quimioter 2006;19:367-75.

17. Yazgi $H$, Ertek $M$, Aktaş AE; Erythromycin resistance of group. A beta-hemolytic streptococci isolated from patients with upper respiratory tract infections. Mikrobiyol Bul 2002;36:11-4.

Source of Support: Nil, Conflict of Interest: None declared. 